Editorial

\title{
Paisajes urbanos céntricos, periféricos, rurales y naturales en América Latina
}

Hoy en día es bien sabido que la rápida urbanización de nuestro continente latinoamericano y su incremento en las últimas décadas ha acarreado cambios en los modos de vida de la civitas tanto en los suelos centrales (Inzulza-Contardo, 2016), como en el deseo por habitar lo extendido y natural, pero sin desconectarse de la urbe. Estos tipos de comportamientos que están generando grandes cambios en los paisajes habitados, sean estos centrales, periféricos, rurales y naturales, convoca al número 37 de Revista de Urbanismo que presentamos a continuación. En primer lugar, se discute la dinámica actual de los espacios edificados que se han gestado tanto en el centro de la ciudad, con expresiones evidentes de sobredensificación y embellecimiento de calles (Zukin et al., 2009), versus la extensión de ella con procesos de periurbanización y sus límites difusos de la rurarización. El trabajo de Jorge Vergara abre los fuegos, con un análisis de la verticalización de las ciudades chilenas, pero desde una aproximación psicológica, señalando que el edificio en altura "concita el interés público", pero que "requiere una comprensión que excede las razones económicas y las posibilidades técnicas que llevan a la proliferación" de esta tipología.

Sin duda, este tipo de propuesta arquitectónica ha masificado y densificado los centros urbanos, lo cual se contrasta con el impacto de políticas de vivienda que presenta Sara Boccolini para el caso de Córdoba, Argentina, dentro del periodo 2001 y 2015. La autora relata cómo dichas premisas han fomentado procesos de contraurbanización, periurbanización, inquilinización, y el vaciamiento de áreas pericentrales en ciudades intermedias. Se pone en valor los resultados de esta investigación que sin duda parecen encontrar eco en la producción de hábitat urbano en áreas metropolitanas, tanto de Argentina como en Latinoamérica en general, coincidiendo con el trabajo de María Martínez, Rolando Reynoso, Miguel Alvarado y Javier Romero y el rápido incremento demográfico en las localidades rurales que conforman la periferia urbana dentro del Estado de
Tlaxcala, México, en un periodo mayor de tiempo: desde el 1980 a la actualidad. Esta situación plantea grandes desafíos en materia de ordenamiento territorial y gestión urbana, requiriéndose de una reorientación de directrices gubernamentales que articulen este crecimiento urbano con "las necesidades concretas de infraestructura, servicios y estrategias de desarrollo requeridas para lograr una integración eficiente, ordenada y sustentable". Luz Cordero y Luis Salinas cierran este primer bloque de trabajos con el análisis dentro de México, pero con lupa en el centro de la ciudad, analizando la gentrificación comercial y cómo los llamados "mercados gourmet" cobran fuerza como modelos contemporáneos de consumo y espacios escenificados, generando alzas de precios que terminan por desplazar al comercio y a la población local.

En un segundo grupo de aportes, se pone de discusión la planificación del territorio y su pertinencia en la adecuada regulación del paisaje rural y natural. Es así como Daniela Rotger analiza el paisaje fluvial en la Región Metropolitana de Buenos Aires, Argentina, específicamente en la cuenca del arroyo del Gato y las posibilidades de integración de este sistema en las políticas de paisaje dentro de los instrumentos de planificación del territorio. En la misma línea, un siguiente trabajo explora los "espacios urbanos verdes" o "urban green spaces" como componente de un ecosistema mayor propuesto por José Vargas-Hernández, Karina Pallagst y Justyna Zdunek-Wielgolaska. Los autores relevan la importancia de generar iniciativas medio ambientales, económicas y sociales para articular estos lugares, lo cual es vital de adquirir por parte de las autoridades locales y con representatividad de todos los actores públicos y privados. Por su parte, Rodimiro Ramos y Miguel Palomeque plantean una modelación del cambio de uso del suelo en Comalcalco, Tabasco, México, tomando como base el efecto provocado por el crecimiento de las actividades antropogénicas sobre las coberturas naturales. Dentro de su análisis cuantitativo, 
se pueden identificar entre 2000 y 2010 grandes pérdidas de vegetación y cuerpos de agua ante el crecimiento acelerado de más de ocho mil hectáreas de uso agrícola y de la zona urbana. La necesidad de un programa de "ordenamiento ecológico" expuesta por los autores se puede, además, reflexionar junto al trabajo de Laura Quintero y su análisis para la recuperación de espacio público mediante infraestructuras verdes en Tunja, Colombia. Esta ciudad en franco crecimiento pone sobre la mesa de discusión la adopción de infraestructuras vegetadas que hagan frente a la desigualdad en la conectividad y desregulación estatal ante la densificación urbana.

Dos trabajos se agrupan para relevar la importancia de habitar en la pendiente y cómo articular este modo de vida con el equipamiento urbano. En primer término, Luis Catalán hace una revisión a las formas de medición de la segregación socio-residencial, por medio de un sistema de doce indicadores social-territoriales que exploran la proximidad y servicios básicos, la vivienda y espacio construido, y la caracterización social y económica, en su aplicación con la unidad vecinal de Viña del Mar, Chile. El autor concluye que la pertenencia del territorio en pendiente no pasa por una administración clásica de este, sino que depende que cómo la comunidad se sirve de servicios y su condición vernacular. En un segundo momento, Omar Cañete invitará a entender la manera de habitar en la quebrada de Valparaíso, Chile, con el desarrollo de modos integrados de comprensión y análisis de la realidad que integren dicha complejidad. Tanto los lazos sociales como la naturaleza del territorio habitado posibilitarían formas de apropiación más idóneas y resilientes para la comunidad.

Esta última idea permite hacer un cierre de los diez trabajos que se presentan en el número, los cuales en su conjunto entretejen reflexiones comunes acerca de cómo se requiere con más fuerza de la comprensión y reconocimiento integrales del territorio habitado latinoamericano y su articulación con el paisaje (Valencia, 2017), por disímil que este sea, como paisaje urbano, rural o natural. Además, el deseo de una función más "urbana-verde" y habitar con calidad de vida no parecen ser aspectos que corren por el mismo carril de la planificación del territorio, por lo que el incentivo al crecimiento sustentable de la ciudades y comunidades sigue siendo un desafío para nuestro continente [B]

Jorge Inzulza-Contardo 2

Editor

Cómo citar: Inzulza-Contardo, J. (2017). Paisajes urbanos céntricos, periféricos, rurales y naturales en América Latina. Revista de Urbanismo, 37, 1-2. https://doi.org/10.5354/0717-5051.2017.47985

\section{Referencias}

Inzulza-Contardo, J. (2016). Contemporary Latin American gentrification? Young urban professionals (YUPs) discovering historic neighbourhoods. Urban Geography, 37(8), 1195-1214.

http://dx.doi.org/10.1080/02723638.2016.1147754

Valencia, M. (2017). Tensiones entre procesos de patrimonialización y modernización neoliberal. El caso de los paisajes culturales modernos: conjuntos habitacionales y barrios obreros en América Latina en el siglo XX. Revista de Urbanismo, 36.

http://dx.doi.org/10.5354/0717-5051.2017.45198
Zukin, S., Trujillo, V., Frase, P., Jackson, D., Recuber, T. \& Walker, A. (2009). New retail capital and neighborhood change: Boutiques and gentrification in New York City. City \& Community, 8, 47-64. http://dx.doi.org/10.1111/j.1540-6040.2009.01269.x 
Revista de Urbanismo, 37, 1-2. 